\title{
Caring for the caregivers - a nursing management perspective
}

\section{A Minnaar, Ph.D,School of Nursing, Decentralised Programmes, University of Natal}

\section{Abstract}

The aim of the study was to explore the practice of caring for the caregivers in selected hospitals in KwaZulu-Natal. A qualitative research approach was used to ensure that the complexities of caring were reflected in the study. The qualitative analysis of the interviews with nurse managers and nurses indicated that they saw caring as an important part of their management task. The participants in the study saw caring for nurses mainly as dealing with the interpersonal aspects of nurses. Caring for nurses was further described in terms of solving the personal problems of nurses, promoting the development and growth needs of nurses with the focus, mainly, on the educational needs of the organisation itself, the welfare needs of nurses with specific reference to their family needs and responsibilities, and a major emphasis on HIV/AIDS issues arising amongst nurses themselves.

\section{Opsomming}

Die doel van die studie was om sorg aan sorgverleners (caring for the caregivers) in uitgesoekte hospitale in KwaZulu-Natal te ondersoek.'n Kwalitatiewe navorsingsbenadering het verseker dat die kompleksiteit van sorg in die studie gereflekteer word. Die kwalitatiewe analise van die onderhoude met verpleegbestuurders en verpleegkundiges het aangedui dat sorg as 'n belangrike deel van die bestuurstaak van verpleegbestuurders gesien is. Die deelnemers aan die studie het sorg aan verpleegkundiges hoofsaaklik as die hantering van interpersoonlike aspekte van verpleegkundiges gesien. Sorg aan verpleegkundiges is verder beskryf in terme van probleemoplossing van persoonlike sake van verpleegkundiges, die ontwikkeling en groeibehoeftes van verpleegkundiges met klem op hoofsaaklik die behoeftes betreffende opleiding binne die organisasie self, die welsynsbehoeftes van verpleegkundiges met spesifieke verwysing na die behoeftes en verantwoordelikhede betreffende hul familie en 'n sterk beklemtoning van MIV/ VIGS onder verpleegkundiges.

\section{Introduction}

This study aimed to explore caring for the caregivers. The phenomenological approach was utilized for the qualitative research to explore the meaning and expectations of caring among nurse managers and nurses and the lived experiences of nurses of being cared for within the context of nursing management (Riemen 1986:85-108). The aim of this study was to explore caring for the caregivers by asking the participants to describe the meaning of caring for nurses in their own hospitals. The qualitative approach was chosen to help the researcher to understand the caring behaviour, and experiences of nurse managers and nurses and the meaning of caring in the context within which they functioned and lived every day. The goal of the qualitative research methodology was to try to understand caring from the point of view of the participants in their context in the hospitals as nurse managers and nurses. The researcher believed that the understanding of caring and the full complexity of human sense making could be lost, if the textual data were quantified.

Nurse managers have a unique responsibility to ensure the well being of nurses and patients and also to ensure that organisational objectives are met (Christensen 1988: 46-55). This principle of beneficence guides the nurse managers actions and refers also to the obligation resting on the nurse to do good to others and not to harm them. The principle of beneficence is often in contrast with bureaucratic systems where individuals experience depersonalisation (Christensen 1988: 46-55). In South Africa at the present time, for instance, nurses have to make do with so little and spend much of their time begging for supplies instead of caring for their patients. A poster on the walls of the Chris Hani Baragwanath hospital underlines this situation. It reads: $A$ Our skeleton staff has been reduced to a bag of bones (Gilbey 2000: 114).

The question is now, who cares for the patients and who cares for these bags of bones?

During the past year many examples of the hard life of nurses were cited in the media, and the lowering of standards in the health services was evident from the conditions in the hospitals. Mngomezulu (2000) (cited in Gilbey 2000:114-122) has said that the culture of caring and compassion amongst nurses has been eroded. Bad publicity has contributed to making the nurses job harder. Nurses are the backbone of the health services and yet they are treated as slave labour. In the Eastern Cape, Thomas (cited in Gilbey 2000: 114-122) blames declining nursing standards amongst other factors, on poor management that has failed to provide effective supervision and encouragement.

Nzimande (1995) asked the question Who cares? in an article 
some years ago in the South African Nursing Times (1995: 1819). She indicated that the health services had been investigating violations of caring rights of patients on the grounds that rights of caregivers were being violated. She suggested that we need to really examine A who cares and what the ethics of caring really were (Nzimande 1995: 18-19).

The research was therefore undertaken to explore caring for the caregivers.

\section{Research objectives}

The specific objectives for the study were to:

Explore the meaning of caring for the caregivers from the point of view of nurse managers and nurses.

Determine the expectations of professional nurses regarding caring as related to the management in nursing.

Identify common themes and practices regarding caring practices in the management of nurses.

\section{Theoretical framework}

The framework that was used for this study was the Caring Theory of Watson (1985: 9-10). Watson (1985:9-10) identified ten (10) carative factors which encourage health and development of individuals, families and communities. The ten carative factors are the formation of a humanistic-altruistic system of values, the installation of faith and hope, the cultivation of sensitivity to ones self and to others, the development of a helping-trust relationship between the care-receiver and the caregiver to ensure a relationship of quality, the promotion and acceptance of the expression of positive and negative feelings, the systematic use of the scientific problem-solving method for decision-making, the promotion of interpersonal teaching and learning, the provision of a supportive, protective, and (or) corrective mental, physical, socio-cultural and spiritual environment, assistance with the gratification of human needs, the allowance for existentialphenomenological forces. Watson (1985: 10) emphasized that no one of the factors could be implemented on its own, and stressed the importance of a philosophical foundation for caring in nursing. The provision of a human value system in nursing management would give nurses an environment conducive to quality nursing care. Nurses should nurture hope in their patients and the nurturing of hope in the management environment could contribute to the willingness of nurses to instil hope in their patients and thus contribute to the recovery process. Watson (1985:41) stated that the recognition and development of feelings helped in the self-actualization and growth of a person. She singled out the main responsibility of the management as being to help nurses towards growth and self-actualization and to enable them to encourage growth in others.

\section{Target population and sampling}

The target population included general provincial and private hospitals in KwaZulu-Natal. The hospitals were identified from the Hospital Yearbook for South Africa (1997). Purposive sampling was applied where the hospitals were selected according to the judgement of the researcher about the most representative hospitals and also to include hospitals with differ- ent financial and service systems to ensure the inclusion of a broad spectrum of the health care that is offered to general patients in KwaZulu-Natal (Polit and Hungler 1993:179-180). Three hospitals were included in the study and the sample consisted of a general provincial hospital, a private hospital and a mission hospital in KwaZulu-Natal. Rational purposive sampling with the following guidelines applied:

1. A medium size non-government hospital in the city with a reputation for caring in nursing care was included. (Hospital 1); 2. A medium size private mission hospital with a reputation for caring was included. (Hospital 2);

3. A medium sized general provincial hospital in a more rural area of the region that was known for quality patient care and with a reputation for caring was included. (Hospital 3).

The purpose and importance of the study was explained to the chief nursing service managers, of each hospital to assess their interest and willingness to participate in the study.

\section{Research methodology}

The principles of phenomenological research were applied to explore the meaning and expectations of nurse managers and nurses and their lived experiences of being cared for as nurses within the context of the management (Riemen 1986: 85). The participants were informed that their experiences should focus on their current positions. Each participant was assigned a code number according to the hospital as an assurance of confidentiality, for example (1.1). The participants were asked to identify a suitable venue, date and time for the interviews. Nurse managers, middle managers and professional nurses were interviewed (20-80 $\mathrm{min}$ ) and the data were audio taped, with consent from the participants. Twelve nurse managers (ten nurse managers; three were nursing service managers in charge of the hospitals, and seven at middle management level and two professional nurses at first level management who were available and willing to participate in the study, were included from the hospitals. Nursing service managers were approached and the participants were asked to volunteer to take part in the study. It seemed to be a problem to interview the nurses in the wards because of the shortage of staff in the hospitals at that time. The data collection was terminated as soon as the data was saturated. A data collection protocol was used with caring concepts as a guide for the interviews. Questions such as: What does caring for the caregivers means in the management context of nurses? Would you describe your health service as a caring service? Do you experience your work setting as a humane (caring) work environment? What do you expect from caring in the management process in nursing? How do you try to create a humane (caring) work setting in your service/unit? were included.

The data was collected in a contextually informed way by capturing not just the words but also the differences in pitch, gestures, body language, silences and simultaneous speech. The raw data, as recorded, was transcribed for each participant. Before working on the data, the researcher needed to identify her own preconceptions on the phenomenon of caring. The researchers own preconceptions needed to be set aside (the process of bracketing). That enabled the researcher to be more open and to validate her own beliefs and concerns 
while recognising that biases cannot be controlled fully.

The data was analysed qualitatively with the help of the computer software program for qualitative data analysis called NUD*IST 4. NUD*IST was used in this qualitative research to explore the meaning of lived experiences of nurse managers and nurses. The interviews and the observations during the interviews were made in natural settings. The steps to be followed were:

\section{Step $1 \quad$ Familiarising and immersion}

The data came in the form of audio taped interviews with participants together with field notes of the researcher. The audiotapes were transcribed and typed into a word processing computer programme. The data was read over and over and after careful thought free nodes were created with a description where applicable. By the time of data analysis a preliminary understanding of the meaning of caring from the perspective of the nurse managers and nurses was formed. The issue of HIV/AIDS emerged from the first interviews and it was clear that nurse managers spent much of their time dealing with it. The data was studied to identify material related to the phenomenon of caring. The data was then searched for deeper regularities and irregularities and for differences and similarities. Units with the same meaning or idea were identified.

\section{Step 2 Coding}

Coding meant breaking the data down in analytically relevant ways (meaningful pieces) (Terre Blanche and Durrheim, 1999:101). The data was coded into free nodes from the interviews. No new free nodes emerged after interview eight, which indicated that the sample was adequate but the research at that stage included only two of the hospitals, and therefore the interviews proceeded to include the third hospital as well.

\section{Step $3 \quad$ Inducing themes}

The bottom-up approach as described by Terre Blanche and Durrheim (1999: 102) was used to organize the data that naturally underlay the material. The content was not being merely summarized but the caring processes and concepts were being kept in mind when organising the data into themes.

After the data was coded sixty-three free nodes emerged from the data. Merging the codes was a tedious process via the computer. The nodes were studied to identify relationships between the nodes. The free nodes were merged by hand and grouped into codes. The major codes from the data were $h u$ manity, problems, needs, HIV/AIDS, illness, funeral support, education, social problems, communication, counselling. Humanity, and the nodes that were related with similar patterns to humanity, was categorised and transformed into a meaningful theme together with general aspects of the human environment into The general aspects of human environment theme. The next theme including communication and interpersonal aspects was grouped into The interpersonal theme.
Problem solving and the nodes concerning problems were categorised into The problem-solving theme. Education and all the nodes on development of nurses were categorised into The development and growth theme. Needs, illness, social problems and the nodes on all the different aspects of the needs of nurses were categorised into The needs theme. HIV/AIDS, counselling, dying of AIDS and funerals were categorised into HIV and AIDS theme.

Step $4 \quad$ Interpretation and checking

This step included the written version of the phenomenon of caring for the caregivers. The interpretation of the phenomenon under study was studied carefully to identify weak points and contradictions in the interpretations. The objectiveness of the researcher was of the utmost importance during this step (Terre Blanche and Durrheim, 1999: 104).

\section{Trustworthiness}

The trustworthiness of the study was demonstrated by the fact that the study was done over a period of three years and that the data was collected from the nurse managers and nurses in their own environment. The documented and transcribed evidence from the interviews was taken back to the participants who confirmed that the transcription was a true reflection of what was said during the interviews. The categories and themes were taken back to the participants for verification. Evidence of the documented patterns and categories was kept for reference and the data collection and analysis were done over a long period of time, (three years). The same patterns and categories of caring were present after interview ten (Poggenpoel 2000: 349-350).

This study shared the main concepts of the theoretical framework of the Caring Theory of Watson (1995) which was used to guide this study. The HIV/AIDS category, which emerged as a new category in caring for nurses in this study, could be an indication of the seriousness of the infection rate and the effect of the disease on the health services currently in KWAZULU-NATAL.

\section{Results}

The results were discussed under the headings of the categories that emerged from the data. Direct quotes from the interviews are typed in italics and are indented in the text. The reference to a specific quote indicates the hospital and the transcript line number, for example $(1,102)$. The text bracketed in italics was added by the researcher for better understanding, for example (love is visible) In some cases to clarify meaning, a word or words may have been altered and this is indicated by square brackets around the alteration, [relieved].

Theme 1: $\quad$ Caring for nurses in terms of general attributes in the human environment

Respondents described caring for nurses in practical terms. One respondent described caring practically by the following example:

(Caring is like) a sewing machine. See, you must look after it, service it and then it will perform well. That is 
what I do to the staff, doctors and all. You got to care $(1,61$ 63).

Caring in nursing management differs from caring in the patient care environment and it seemed to be a problem for some nurse managers to apply the caring concepts in nursing management and for nurses to perceive it as caring. This difficulty was illustrated by the following:

I think hmm, the first thing that comes to my mind is that it is ever so much more difficult than in the nursing context. We have been taught to be nurturers and to be carers and to be people who are hands on in the sense that if someone is uncomfortable I relieve their pain. If somebody is untidy, I will clean them up. If someone is bleeding I will stop the bleeding and my interpretation of care is with my hands. Now suddenly in a managerial position, hmm, I am trying to care without that direct contact, physical contact. I really think that we do not prepare our nurse managers [for] how difficult that is (2, 316-337).

In comparison with the work of Watson (1985: 10-16) the descriptions as given by the participants in the main theme, general attributes of caring in the human environment such as kindness, concern and love, were caring concepts grounded in humanistic values which bring meaning to one s life through other people according to factor three of Watson (1985:17). The instilling of faith and hope (factor two of Watson, 1985:13) was not evident in the interviews. Watson (1985:13) described the instilling of faith and hope as the inspiration of the mind and soul so that the illness of a patient could then be treated. Faith and hope could be instilled as a caring attribute in the nursing management environment as an inspiration of nurses towards growth and development. Understanding and acceptance of the nurse as an individual, (factor three of Watson, 1985) were clearly described by the participants.

\section{Theme 2: $\quad$ Caring for nurses in terms of interper- sonal relationships.}

Caring in terms of interpersonal relationships with other people was described by the participants in various ways and by using different expressions. This main theme included affiliation needs of individuals in relation to other people in interpersonal relationships. The management of nurses is an interactive process and therefore emphasis was placed on relationships and interaction. The interest in, and openness to nurses and the availability of nurse managers to assist nurses in the nursing situation that were described by the participants were indications of how important nurse managers rate these aspects in their management functions in the health services.

Communication and listening were clearly defined from the nurse managers point of view and nurse managers indicated aspects related to communication and pointed out the aspects they (nurse managers) thought nurses expected from them:

I feel part of the team and I want them to know that I am there for them, should they encounter problems. We have meetings, every month, with my staff where we look at patient management, human relationships, and the medical staff also joins us in meetings. So we generally discuss problems and solutions and we look at solutions and we plan together. We schedule our meetings once a week so that we meet with everybody (1,671-673).

In comparison with Watson (1985: 23-40) the categories for behaviour and relationships between human beings were in line with the nursing management situation in health services. The five categories of behaviour are according to Watson (1985:25) living with another, co-operation with others, establishing a healthy emotional and physical environment, establishing a bond and nurturing and accepting others. Aspects of the categories that were included were communication and listening to the other, and interest in the other person and knowledge of him/her. The openness to each other to establish a bond and availability to assist the other were emphasised and referred to by the participants in this study.

\section{Theme 3: $\quad$ Caring to nurses in terms of problem solv- ing.}

Problem solving and identification of problems seemed to form a major part of the job of a nurse manager. An interesting fact that came to the fore was that problems seemed to be more social problems of staff than patient care problems, as would be expected. The participants indicated that problems were shared and means to solve the problems were in place such as discussing the problem. Referrals were done if necessary, for example:

You counsel her, and look at options like, for instance, if she persistently comes late on duty and when she tell you about this problem, then you talk with her and perhaps suggest, how about taking her (mother that she is looking after) to a home, inviting a relative to assist her, and look after [her] mother and give [her] a break so that [she can] actually concentrate on [her] work. So you plan together with her but she takes the leading part $(1,725-730)$.

Problem solving was an important part of caring in the sense that nurses, particularly the nursing students, needed knowledge and understanding for the application of the problemsolving and decision-making process in nursing (Watson 1985:51-66). The components, such as assessment, analysis and diagnosis, planning, implementation and evaluation of the problem-solving process, did not emerge clearly from the discussions with the participants. The counselling of nurses was indicated by the participants as an important aspect of problem solving.

\section{Theme 4: $\quad$ Caring for nurses in terms of development and growth.}

Growth and development of staff was identified as a major theme in caring and for the purpose of this research it was categorised as a major theme. Growth and development, participative management and feedback formed a major part of the theme on growth and development. Caring was understood as helping the other to grow, and therefore mentoring and leading by example formed important aspects of the growth process, which was described in detail and many examples 
were given as to how the development of nurses was being dealt with, for example:

\begin{abstract}
Personally my greatest joy is watching people grow and take off. I really love it when you have worked yourself out of $a$ job and somebody else takes off with it, and they even stop talking about you having been associated with it and now talk about that person running it $(2,389-392)$.
\end{abstract}

Leading by example was very prominent in one hospital only. The synonym for leading by example, such as role modelling was also mentioned by the other hospitals. At the one hospital, however, one participant described leadership and development. It seemed that the participant who commented on this aspect believed strongly in leading by example and role modelling. It was expressed as something one should do although no examples were given of how actually to lead by example:

They got to see you doing it and once they see you are doing that most of the time they will copy it besides you teaching it $(1,49-50)$.

Well, I think we should set an example as leaders. We should be exemplary because you cannot expect the subordinate to be caring if you do not have that attitude $(1,408-410)$.

In the comparison with the theory of Watson (1985: 69-79) development and growth of nurses is described as the teaching-learning process in nursing as it engaged both the nurse and the other person. It includes the issues of information as well as consideration of the nature of learning and what interpersonal processes facilitate learning. Nursing educators always maintain that health teaching is one of the main functions of a nurse. According to Watson (1985, p. 79) The science of caring concerns itself theoretically and practically with all the aspects of interpersonal teaching-learning $\mathrm{A}$ supportive and corrective environment provides for a person s mental, spiritual and socio-cultural harmony and well being. Nyberg (1993: 13) makes it clear that caring requires us to recognize the potential of people we care for, by empowering them and not by having power over them. Caring makes the nurse manager different from other managers in that caring defines the behaviour and attitude of the nurse manager in a more relational and growth-orientated way. It also asks for openness, listening to and valuing of the other while the goals of the organisation stay important. The duties do not change in caring management but the manner in which one goes about executing it does. The use of power changes to empowerment and growth and development and this is a constant challenge for nurse managers.

\section{Theme 5: $\quad$ Caring for nurses in terms of needs.}

The identification of needs was categorised according to Maslow (cited in Booyens 1998: 458) in the lower, social and higher categories of needs.

Lower order needs that include the physiological and security needs, such as comfort, spiritual needs, welfare of nurses, enough equipment and safety, were aspects that were identified by the participants. These identified needs could contribute to an environment that is conducive for nurses to render quality patient care in the hospitals. Basic to the environment created for the nurses is enough equipment at the disposal of nurses in the health services. This need was emphasised by participants as follows:

I make sure that nurses, so called understaffed or stressed, have got everything they need in order to function. Now I put a lot of energy into that. You know making sure that every single one of my nurses has got everything that she needs. I have learned to turn that into my concept of caring, if I can make sure of that, and know that the nurses in my area have got absolutely everything to achieve patient care, I see that as part of my caring role (2, 363-368).

Social needs are, according to Maslow (cited in Booyens, 1998:458), the needs of employees to take part in social activities in the hospitals. After the satisfaction of physiological and safety needs, social needs (belonging needs) become predominant. Social needs, the affiliation needs of nurses, were seen to and examples of socialisation within the hospitals are:

[There is] a netball club in the hospital. The nurses organise it in their own time in lunch times. And when they have to go to tournaments I make arrangements for them to go by asking others to relieve them. With music as well, we have a hospital choir that practises during their lunch time and a football club for the males that helps with teambuilding $(3,143-147)$.

The higher needs or self-actualisation needs were dealt with to a great extent under the growth and development theme and should be seen as part of this need as well

In comparison with Watson (1985:81-100), nurse managers addressed the needs of nurses to a certain extent by putting the emphasis on personal problems of nurses due to illness and family problems.

\section{Theme 6: $\quad$ Caring for nurses in terms of HIV and AIDS}

HIV/AIDS was identified as a major theme in caring for the caregivers. For the purpose of this research it was categorised as a major theme because of the emphasis placed on it by nurse managers. HIV/AIDS and the problems associated with it seemed to take up a lot of the time of nurse managers. It also seemed important to look at the competencies needed by nurse managers to deal with the complex problems and the demands that this killer disease put on nursing resources.HIV/AIDS and support to the families of nurses with the disease seemed to be a major issue because of the influence of it on health services and the nurses themselves. Nurse managers saw caring for nurses to a great extent as dealing with the disease and 
support to the families of nurses. Nurse managers saw their caring task as supporting the staff members in dealing with the disease and organising the funerals of staff members who died of AIDS. Support to nurses was described from the context of illness or HIV/AIDS and not in the context of true caring to help the nurses to grow and develop in their professional lives. The following were examples described by the nurse managers:

We nursed her here and when she died I communicated with her mother, because she was a breadwinner, and I asked her mother if there was a sister who was actually big enough to get employment at the hospital, then I discussed it with the management, and w'e all agreed that we should offer this family assistance, because it was a very, very poor family: So what I did I asked the mother to bring the sister here, I interviewed the sister and I employed her as a general assistant. She was qualified and did a secretary course after standard ten. But she accepted the post as an assistant. I did not have a post for a secretary with the hope when there is a post in admin, then she can apply for it, she was employed here. Unfortunately she also contracted HIV/ AIDS and she died, she died two months ago $(3,47-58)$.

Caring for nurses was mainly referred to in terms of AIDS counselling and support as follows:

Hmm, hmm I can go into lots of caring. We do AIDS counselling. I myself am an AIDS counsellor. I do know' some of the staff are HIV positive and in the allocation list, (I do the allocation), I try to place them in suitable departments. For a lot of them, I have torn up the HIV results and keep it confldential. I think also in the office here, confidentiality play's a very important role (3, 207-212).

Nursing is dow'n because the nurses themselves are sick, they are sick with HIV and in all these wards the patients (twelve a day die), gone dead, they are dying, that is so demoralising and they even said you know' they are going to die and even themselves (the nurses) they die by HIV/AIDS $(1,33-36)$.

With the few resources they always have a complaint, we are oveniorked, because they (the nurses) are sick. They don't come on duty, they stay off sick, put in leave again and again because their immune system has gone doun. Flu, so many lof the nurses] have flu they stay away with flu for two months. No doctor's certificate is presented, that is a problem $(1,43$ 48).

Care for dying staff was very prominent at the hospitals and it was expressed as follows:

They want the matron to visit them at the hospital and they want the management to be there at the nurse's funeral and to take a lead in organising the nurse's funeral, especially the African nurses. The other races are not a problem, but the African nurses want the management to get involved in organising the funerals for a nurse who dies, and the management to be there at the funerals $(3,105$ 110 ).

Employees, who have HIV/AIDS, were managed well by nurse managers in the health services. Employees living with HIV/ AIDS will be productive for a long period if they receive the medical, social and psychological support they need. It is important to develop guidelines and policies for managers to assess and manage the situation (Davies, Schneider, Rapholo and Everatt 1997:10-15).

HIV/AIDS is never far from the headlines and the scenario that was created at the Nursing 2000 Conference in Midrand during the first week in September 2000 indicated that twenty percent of the South African nursing population could theoretically be HIV positive. That means that of the 174000 nurses available for duty in South Africa, 34000 nurses could be HIV positive and one student nurse would die of AIDS every month, (Geyer 2000:1). The Gauteng Department of Health indicated that there is no proof of these statistics and it is not clear how these figures were leaked and questions are being raised about their accuracy.

The fact that nurse managers spend a lot of their time on HIV/ AIDS related aspects, could be an indication of the seriousness of the infection rate and the effect of the disease on the health services. Nurse managers indicated that they spend a great deal of their time on counselling nurses with HIV/AIDS, care of the ill nurses, and organising funerals of nurses who have died of AIDS and related diseases.

\section{Discussion of caring for the caregivers}

The general aspects of the human environment were described with an explanatory comparison of caring in nursing management by a participant, in terms of the maintenance of a sewing machine. The example implied that if you look after the nursing staff and you keep them up to date and supply the nurses with well functioning equipment, they will perform well and give high quality nursing care. This view of the nurse managers was in agreement with the view of Kurtz and Wang (1991) (cited in Barker, Renolds and Ward 1995:386-397) that for nurses to be caring with their patients, they must experience and feel cared for by nurse managers.

Concern was expressed by a participant that nurses were taught to nurture and care for patients with their hands but when a nurse became a manager then the nurse must care and be caring in another dimension, without direct and physical contact with the person. Nurse managers should be prepared to make the shift from direct care to a more indirect type of care when they become nurse managers. Nyberg (1993:11) holds the view that the duties of the nurse manager do not change, but how one goes about those duties differs. The management functions need to be more flexible, and interactive decision-making should be the norm in the health services of today. 
Caring in terms of interpersonal relations and interaction was described as communication and listening and this was emphasised as very important in the management of nurses. Twoway communication seemed to be a problem in nursing in the sense that the message from the top did not always reach the bottom. Nurse managers expressed their concern with the fact that nurses were unable to perceive the message at some stages.

Problem solving received less attention from nurse managers and it was referred to as the solving of social problems of nurses and not problems related to patient care as had been expected.

The focus of caring for nurses in terms of development and growth was well described by nurse managers by providing opportunities to nurses and allowing nurses to improve their skills and rectify mistakes. A lot of time and effort was spent on in-service education to meet the needs of the health services, and not so much to meet the needs of the nurse herself in her own professional development.

Caring in terms of needs fulfilment focused mainly on the welfare, illness and family needs of nurses outside the work place, (the lower level needs of Maslow). The fulfilment of the lower level needs of nurses was emphasised by the efforts of nurse managers to ensure that nurses have got everything they need in order to render patient care in the health services.

Nurse managers saw their caring role for nurses with HIV/ AIDS mainly as supportive, being involved in family problems and counselling and guiding nurses living with HIV/AIDS. Nurse managers were involved in planning and organising the funerals of nurses who died from HIV/AIDS. The nurse managers seemed to play a major role in counselling the nurses suffering from HIV/AIDS in the health services. Nurses needed counselling not only because they contracted the disease, but also to help them to cope with the changing demands of the high number of patients who no longer recover from their illnesses, but die as a result of AIDS.

If the scenario which was painted during the Nursing 2000 Conference in Midrand (Geyer 2000:1) is true where the indication was that $20 \%$ of the nursing population might be HIV/ AIDS positive, with an estimation of 34,000 nurses HIV/AIDS positive in South Africa, then the emphasis that was put on this issue by the nurse managers in this study, should be seriously considered in the training and development of nurse managers currently and for the future.

\section{Conclusions}

The qualitative nature of this research study enabled the identification of a major theme in caring for the caregivers, namely caring for nurses in terms of HIV/AIDS. Participants put a great deal of importance on the various aspects related to HIV/AIDS of nurses during the study. It was clear that caring in nursing management was an important function to the participants. On the whole the reflections on the meaning of caring for the caregivers in the management of nurses were inter- esting and surprising. Caring for the caregivers was seen as keeping the nurses in a good physical condition to enable them to do the job. The physical welfare of nurses was seen as very important by nurse managers. Two-way communication was seen as an important aspect of caring for the caregivers and nurse managers made it clear that communication with nurses was open at all times. Nurse managers were aware of the fact that communication in the hospitals was a problem at certain stages and that communication could be distorted and blocked at times.

It was clear from this study that nurse managers were knowledgeable on caring but in their management role their descriptions of caring for the caregivers in the management reflected mainly concern about the physical well being of nurses and support to nurses in dealing with HIV/AIDS issues. The major emphasis that nurse managers placed on HIV/AIDS issues such as support, guidance and counselling of nurses on their HIV/AIDS illnesses, problems and the organising and attending of the funerals of the nurses should be seen in the light of the crisis currently in the health services regarding the handling of the number of HIV/AIDS cases in KwaZulu- Natal.

\section{Recommendations}

Nurse managers must be made aware that caring for the caregivers includes not only illness and HIV/AIDS issues, but many other caring concepts and aspects as well. The caring task of nurse managers is aimed at all the staff, including the wellness of nurses as a whole. Nurse managers and nurses should receive information on the caring theory of Watson (1985) and the practical application of it in the management of nurses. Clearly caregivers can no longer define quality by their standards (structural processes) only. The standards should be the foundation for services and for continuous improvement of caring in the human resources of nurses. Furthermore the following recommendations were made in the study:

\section{Recommendations for caring for the caregivers regarding research:}

- A survey should be undertaken to assess the current situation regarding HIV/AIDS amongst nurses, to enable appropriate planning.

- The effect of HIV/AIDS on the health delivery system should be researched further to establish the needs of nurse managers regarding support, guidance, counselling and care to dying nurses.

- The influence of HIV/AIDS positive nurses on the management of the hospitals should be estimated and additional support systems should be put into place.

\section{Recommendations for caring for the caregivers regarding nursing services:}

- The ability of nurses living with HIV/AIDS should be established and their capabilities to render nursing care should be investigated to enable nurse managers to supply enough nurses to do the job.

- Sufficient additional support and guidance to nurse 
managers and nurses should be provided to cope with the demands of HIV/AIDS positive nurses.

Recommendations for caring for the caregivers regarding nursing education:

- $\quad$ The nurse managers should attend workshops and discussion groups on caring for nurses. In these workshops, caring in the management strategies should be planned strategically.

- Caring for the caregivers as part of the management should be emphasised in the curriculum of all the nursing courses for registration as a professional nurse.

\section{Conclusion}

Nurse managers need basic traditional management skills together with caring attributes in the management of nurses in health services of today. Furthermore nurse managers need specialized skills, in dealing with the impact of HIV/AIDS on nurses and health services. The organisation-wide caring philosophy could be enhanced by enlisting the nursing staff in the whole process, discussion of and reviewing the concepts identified as problematic in this study and relating them to nursing practice and care for the caregivers. The next step should be the formulation of caring standards and behavioural criteria and development and implementation of an educational and marketing plan. It came to the fore that management skills were needed but these are not enough to survive in the current health services. Therefore the decision to train nurse managers and to upgrade the management knowledge and the implementation of the practice of caring concepts in nursing management with relevant care and support for HIV/ AIDS nurses, is of the utmost importance, to equip nurse managers to survive in these demanding circumstances.

\section{References}

BARKER,PJ; REYNOLDS,W AND WARD, T 1995: The proper focus of nursing: A critique of the caring ideology. International Journal of Nursing studies. 32 (4): 386-397.

BOOYENS, S W 1998: Turnover. (In: Booyens, S W Ed. 1998: Dimensions of Nursing Management, Cape Town: Juta, pp 369-379).

BRANDT, M A 1994: Caring leadership: Secret and path to success. Nursing Management. 25 (8): 68-72.

CHRISTENSEN, P J 1988: An ethical framework for nursing service administration. Advances in Nursing Science. 10 (3): 46-55.

DAVIS, S; SCHNEIDER, M; RAPHOLO, \& EVERATT, D 1997: Guidelines for developing a workplace policy and programme on HIV/AIDS and STDs. Department of Health: Pretoria.

GEYER, N 2000: AIDS statistics in perspective. Nursing
Update. 24(10) October:1(col2).

GILBEY, C 2000: Nurses under fire. Femina. November 2000:114-122.

KERFOOT, K 1997: Leadership - The courage to care. Nursing Economics. 15 (1): 50-51.

MORSE, J M 1989: Qualitative Nursing Research A Contemporary Dialogue. Rockville: Aspen Publications.

MORSE, J M; BOTTROFF, J; NEANDER, W AND SOLBERG, S 1991: Comparative analysis of conceptualizations and theories of caring. Image Journal of Nursing Scholarship. 23 (2): 110-126.

NYBERG, J 1989: The element of caring in nursing administration. Nursing Administration Ouarterly. 13 (3): 9-16.

NYBERG, J 1993: Teaching caring to the nurse administrator. Journal of Nursing Administration. 23 (1):11-17.

NZIMANDE, P 1995: Who cares? South African Nursing Times. January: 18-19.

OILER, CJ 1986: Phenomenology: The method.(nㅡ:P. Munhall and C J Oiler Ed. 1986: Nursing research A Qualitative Perspective. Norwalk: Appleton-Century-Crofts, pp69-84).

POGGENPOEL, M 2000: Data analysis in Qualitative research. (In:A. S. de Vos Ed. 2000: Research at grass roots. A primer for the caring professions. Pretoria: Van Schaik Publishers, pp 334-353).

POLIT, PF \& HUNGLER, B P 1991: Nursing Research: Principles and methods, 4th edition. Philadelphia: Lippencott.

RIEMEN, D J 1986: The essential structure of caring interaction: Doing phenomenology ( In: P Munhall and CJ Oiler Ed.1986: Nursing research: A Qualitative Perspective Norwalk: Appleton-Century-Crofts, pp 85-108).

TERRE BLANCHE, M \& DURRHEIM, $K$ 1999: Research in Practice. Applied methods for the social sciences. Cape Town: UCT Press.

WATSON, J 1985: Nursing, Human Science and Human Care: A Theory of Nursing. Norwalk: CT Appleton.

YOUNG, S Ed. 1997 : Hospital and Nursing Yearbook. Pretoria: Pharmaceutical Printers and Publishers. 